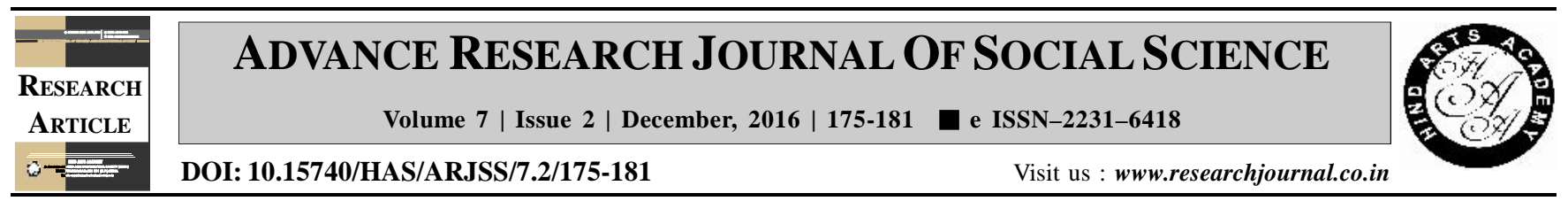

\title{
Occupational stress of men and women police
}

Daneshwari Onkari* and Sunanda Itagi

Department of Human Development and Family Studies, College of Rural Home Science, University of Agricultural Sciences, DHARWAD (KARNATAKA) INDIA

(Email: daneshwarimonkari@gmail.com, itagi.sk@gmail.com)

\section{ARTICLE INFO :}

$\begin{array}{lll}\text { Received } & : & 28.05 .2016 \\ \text { Revised } & : & 03.10 .2016 \\ \text { Accepted } & : & 18.10 .2016\end{array}$

\section{KEY WORDS :}

Occupational stress, Role conflict, Role ambiguity, Role overload

\section{HOW TO CITE THIS ARTICLE :}

Onkari, Daneshwari and Itagi, Sunanda (2016). Occupational stress of men and women police. Adv. Res. J. Soc. Sci., 7 (2) : 175-181, DOI: 10.15740/HAS/ ARJSS/7.2/175-181.

*Author for correspondence

\begin{abstract}
A study on occupational stress of men and women police was carried out in the year 2014-15 in Dharwad taluk with the objectives to assess the occupational stress of men and women police and to know the relation between selected demographic variables with occupational stress of police. A total of 120 police belonging to 21-60 years age group were randomly selected from 22 police stations of Dharwad taluk. The occupational stress was assessed using occupational stress scale developed by Srivastav and Sing, 1984, socio-economic status was assessed using socio-economic status scale developed by Aggarwal et al. (2005) and self structured questionnaire were used to collect information. The data was collected through questionnaire method along with personal interview of the respondents. The results revealed that 58.33 per cent of police had moderate level of occupational stress followed by high and low level (35\% and $6.67 \%$, respectively). Occupational stress had significant and positive relationship and duty period, distance travelled between residence and work place pointing out that higher the duty period and distance between residence and work place increases stress. There was significant and negative relationship between family size and occupational stress indicating that higher the family size decreases the stress. There was no significant relationship between age, education, marital status, work experience, work satisfaction, socio-economic status and occupational stress.
\end{abstract}

